\title{
The Effect of Sacubitril/Valsartan in a Dialysis Patient with Severe Heart Failure*
}

\author{
Pingping Kong ${ }^{1,2}$, Yanna Dou ${ }^{1,2 \#, ~ X i a o y a n g ~ W a n g 1,2, ~ J i n g ~ X i a o ', 2, ~ Z h a n z h e n g ~ Z h a o ~}{ }^{1,2 \#}$ \\ ${ }^{1}$ The Nephrology Centre Department of the First Affiliated Hospital of Zhengzhou, Zhengzhou, China \\ ${ }^{2}$ Nephrology Institute of Zhengzhou University, Zhengzhou, China \\ Email: "douyanna1982@126.com, ${ }^{*}$ zhanzhengzhao@zzu.edu.cn
}

How to cite this paper: Kong, P.P., Dou, Y.N., Wang, X.Y., Xiao, J. and Zhao, Z.Z. (2021) The Effect of Sacubitril/Valsartan in a Dialysis Patient with Severe Heart Failure. Case Reports in Clinical Medicine, 10, 197-202.

https://doi.org/10.4236/crcm.2021.107025

Received: June 15, 2021

Accepted: July 19, 2021

Published: July 22, 2021

Copyright (๑) 2021 by author(s) and Scientific Research Publishing Inc. This work is licensed under the Creative Commons Attribution International License (CC BY 4.0).

http://creativecommons.org/licenses/by/4.0/

\section{(c) (i) Open Access}

\begin{abstract}
Heart failure (HF) is a major comorbidity in patients with end-stage renal disease (ESRD). The pathogenesis of HF in patients on renal replacement therapy represents the confluence of several traditional and nontraditional vascular risk factors, unique to the milieu of chronic kidney disease and the dialysis modality [1]. The purpose of this report is to describe the efficacy and safety of sacubitril/valsartan for an ESRD patient on hemodialysis therapy conmbined with heart failure with reduced ejection fraction (HFrEF). A 35-year-old woman was undergoing hemodialysis due to ESRD and suffering from heart failure with reduced ejection fraction. Because of worsening heart failure and hypertension, she was prescribed with sacubitril/valsartan at a dose of $50 \mathrm{mg}$ twice a day, spironolactone at a dose of $20 \mathrm{mg}$ three times a day and metoprolol at a dose of $23.75 \mathrm{mg}$ once daily. There was a symptomatic improvement with the heart failure and reduction in NT-proBNP level, accompanied by a decrease of blood pressure after using sacubitric/valsartan. In conclusion, it is safe and effective to take sacubitril/valsartan in this hemodialysis patient with severe heart failure.
\end{abstract}

\section{Keywords}

End Stage Renal Disease, Sacubitril/Valsartan, Hemodialysis, Heart Failure, Reduced Ejection Fraction

\section{Introduction}

Cardiovascular disease is the main cause of death in maintenance hemodialysis patients. Many studies have shown that the proportion of dialysis patients complicated with heart failure is as high as $45 \%$ [2] [3] [4]. Heart failure is the most *An informed consent was obtained from the patient.

\#Corresponding author. 
common and serious cardiovascular complication of dialysis patients, with a very high incidence and poor prognosis, which is an important reason for the progress and death of patients [5] [6]. The treatment of maintenance hemodialysis complicated with heart failure is inhibition of RAAS system (Angiotensin-converting enzyme inhibitors (ACEIs), angiotensin receptor blockers (ARBs) and aldosterone antagonist), control of hypertension, Beta-blockers, statins, etc [7]. Sacubitril/valsartan, which combines an angiotensin receptor blocker (valsartan) with a NEPi (sacubitril), was the first angiotensin receptor-neprilysin inhibitor to be developed. Natriuretic peptide system (NPS) is a kind of neuroendocrine system. It has many beneficial functions, including natriuretic, diuretic, vasodilator and anti regulation of RASS. Neprilysin (NEP or neutral endopeptidase) is the key enzyme responsible for degrading natriuretic peptides. Sacubitril/valsartan consists of the neprilysin inhibitor sacubitril and the ARB, which strengthens the protective neuroendocrine system of the heart while inhibiting the renin-angiotensin-aldosterone system, was superior to enalapril in reducing the risks of death and of hospitalization for heart failure. The PARADIGM-HF trial showed that sacubitril/valsartan reduced the risk of cardiovascular mortality among patients with heart failure with reduced ejection fraction when compared with the angiotensin-converting enzyme inhibitor enalapril, several trials in populations with heart failure. The UK HARP-III trial (United Kingdom Heart and Renal Protection-III) has demonstrated that, compared with irbesartan, sacubitril/valsartan further reduces both blood pressure and biomarkers of cardiovascular risk (troponin I and N-terminal pro-B-type natriuretic peptide), and in a wide range of people with proteinuric chronic kidney disease, adding neprilysin inhibition to angiotensin II receptor blockade has no additional effect on kidney function or albuminuria [8] [9] [10]. However, there were less reports on tolerability and outcome of patients with hemodialysis patients. The purpose of this case is to report the efficacy and safety of sacubitril/valsartan in the treatment of ESRD patients with HFrEF.

\section{Case Report}

A-35-year-old hemodialysis female patient was evaluated for heart failure with reduced ejection fraction (EF). Six years ago, she suffered from pre-eclampsia at 33 weeks of pregnancy. The patient was diagnosed with nephrotic syndrome and creatinine level reached $595 \mathrm{umol} / \mathrm{L}$. After the termination of a pregnancy, she received the renal biopsy. The pathological results of renal biopsy showed focal proliferative sclerosis IgA nephropathy with pre-eclampsia pregnancy-induced renal damage. The patient was given the CCB (calcium Chanel blocker) to control the blood pressure. However, she didn't go to the hospital for regular review. Two years ago, the patient had severe chest distress and she couldn't climb the stairs. Her blood pressure was 160/100 mmHg and BNP level had reached 70,000 $\mathrm{pg} / \mathrm{ml}$. At that time, severe renal impairment appeared with high creatinine value of $714.5 \mathrm{umol} / \mathrm{l}$ and low glomerular filtration rate of $5.89 \mathrm{~mL} / \mathrm{min}^{-1} / 1.73 \mathrm{~m}^{2}$. The patient began to receive hemodialysis and anti-hypertension medications 
with CCB (calcium Chanel blocker) and Beta blockers. One year ago, the patient suffered severe chest tightness and inability to lie down at night, she was hospitalized in the department of cardiology. Despite medical therapy, she was 3rd times hospitalized because of decompensated heart failure. Physical examination revealed blood pressure of 140/100 and mild pitting edema in both lower extremities. The serum creatinine was $642 \mathrm{umol} / \mathrm{L}$ and an estimated glomerular filtration rate of $6.65 \mathrm{~mL} / \mathrm{min}^{-1} / 1.73 \mathrm{~m}^{2}$. She also had renal anemia and secondary hyperparathyroidism. The patient was assessed as NYHA (New York Heart Association) class 4 heart failure. The parathyroid hormone was $827.5 \mathrm{pg} / \mathrm{ml}$, albumin was $33.7 \mathrm{~g} / \mathrm{L}$ and the hemoglobin was $118 \mathrm{~g} / \mathrm{L}$ at that time. The NT-proBNP level was $385,000 \mathrm{pg} / \mathrm{ml}$. The echocardiography showed the Left ventricular function was depressed with an ejection fraction $28 \%$ and severe mitral regurgitation with a regurgitant area of $15.1 \mathrm{~cm}^{2}$ (Table 1). She also had severe pulmonary hypertension that pulmonary artery pressure was estimated to be 56 $\mathrm{mmHg}$ and tricaspid incompetence with a regurgitant area of $12.7 \mathrm{~cm}^{2}$. She was treated with $1.5 \mathrm{ug}$ of calcitriol twice a week. She received the dose of $50 \mathrm{mg}$ sacabitril/valsartan twice a day, $20 \mathrm{mg}$ of spironolactone once a day and $23.75 \mathrm{mg}$ of metoprolol once a day. The dialysis protocol of the patient was as follows: hemodialysis (HD) 5 times every two weeks and hemodiafiltration (HDF) once every month. She received high-throughput dialysis with a blood flow of 250 $\mathrm{ml} / \mathrm{min}$ and a dialysate flow rate of $500 \mathrm{ml} / \mathrm{min}$. After 1 year of active treatment, the hypertention was well controlled and there was no symptomatic hypotension. The parathyroid hormone value of the patient decreased from $827.5 \mathrm{pg} / \mathrm{ml}$ before treatment to $605.1 \mathrm{pg} / \mathrm{ml}$ at the $6^{\text {th }}$ month after treatment and $366.4 \mathrm{pg} / \mathrm{ml}$ at the $12^{\text {th }}$ month of treatment (Table 2). The albumin value also increased to the normal level. Moreover, the functional class improved from NYHA 4 to NYHA 1. Both left and right ventricular diameters estimated by echocardiography were decreased. The left ventricular diameter decreased from $23 \mathrm{~mm}$ to 12 $\mathrm{mm}$ and the right ventricular diameter decreased from $59 \mathrm{~mm}$ to $46 \mathrm{~mm}$ (Table 3). Severe tricuspid regurgitation and pulmonary hypertension also got improved and pulmonary artery pressure decreased from $56 \mathrm{mmHg}$ to $14 \mathrm{mmHg}$. The ejection fraction increased from $28 \%$ to $66 \%$ and the NT-proBNP value decreased from $385,000 \mathrm{pg} / \mathrm{ml}$ to $1092 \mathrm{pg} / \mathrm{ml}$. Now, the patient's heart failure symptoms have improved significantly, and the echocardiography indicators have improved compared to before. Because patient has been insisting on taking sacubitril/valsartan, the frequency of hospitalizations due to cardiovascular complications is also decreasing. We will continue to follow-up the condition of this patient.

\section{Discussion}

Cardiovascular events are the leading causes of death in patients with chronic kidney disease. Patients with chronic kidney disease receiving hemodialysis are often complicated with heart failure, and cardiac dysfunction is closely related to renal dysfunction. 
Table 1. Initial echocardiography report of this patient.

\begin{tabular}{|c|c|c|c|c|}
\hline $\begin{array}{l}\text { Right ventricular } \\
\text { diameter } 23 \mathrm{~mm}\end{array}$ & $\begin{array}{l}\text { Ventricular septal } \\
\text { thickness } 14 \mathrm{~mm}\end{array}$ & $\begin{array}{l}\text { Left ventricular } \\
\text { diameter } 59 \mathrm{~mm}\end{array}$ & $\begin{array}{l}\text { Left ventricular } \\
\text { posterior wall } 13 \mathrm{~mm}\end{array}$ & $\begin{array}{l}\text { Aortic ring } \\
\text { diameter } 21 \mathrm{~mm}\end{array}$ \\
\hline $\begin{array}{l}\text { Left atrial } \\
\text { diameter } 43 \mathrm{~mm}\end{array}$ & $\begin{array}{l}\text { Ascending aorta } \\
\text { diameter } 41 \mathrm{~mm}\end{array}$ & $\begin{array}{l}\text { Pulmonary artery } \\
\text { ring diameter } \\
24 \mathrm{~mm}\end{array}$ & $\begin{array}{l}\text { Pulmonary valve } \\
0.73 \mathrm{~m} / \mathrm{s}\end{array}$ & $\begin{array}{l}\text { Right atrium } \\
49 \times 65 \mathrm{~mm}\end{array}$ \\
\hline E peak $0.99 \mathrm{~m} / \mathrm{s}$ & A peak $0.37 \mathrm{~m} / \mathrm{s}$ & $\begin{array}{l}\text { Aortic valve } \\
0.97 \mathrm{~m} / \mathrm{s}\end{array}$ & $\begin{array}{l}\text { Tricuspid } \\
\text { regurgitation } 3.1 \mathrm{~m} / \mathrm{s}\end{array}$ & $\begin{array}{l}\text { Pulmonary artery } \\
\text { pressure } 56 \mathrm{mmHg}\end{array}$ \\
\hline EDV $295 \mathrm{ml}$ & ESV $212 \mathrm{~m}$ & LVEF $28 \%$ & $\begin{array}{l}\text { Mitral valve orifice } \\
\text { regurgitation area } \\
15.1 \mathrm{~cm}^{2}\end{array}$ & $\begin{array}{l}\text { Tricuspid } \\
\text { regurgitation area } \\
12.7 \mathrm{~cm}^{2}\end{array}$ \\
\hline
\end{tabular}

EDV: End Diastolic Volume; ESV: End Systolic Volume; LVEF: Left Ventricular Ejection Fraction.

Table 2. Comparison before and after taking sacabitril/valsartan.

\begin{tabular}{cccc}
\hline & 2019.1 & 2019.6 & 2019.12 \\
\hline BP (mmHg) & $159 / 100$ & $145 / 100$ & $122-145 / 72-96$ \\
ALB (g/L) & 32.2 & 44.7 & 41.7 \\
Blood phosphorus & 0.94 & 0.79 & 0.6 \\
PTH (pg/ml) & 827.5 & 605.1 & 366.4 \\
URR (\%) & 65.8 & 74.6 & 75.4 \\
KT/V & 1.3 & 1.64 & 1.63 \\
\hline
\end{tabular}

BP: Blood pressure. ALB: albumin. PTH: parathyroid hormone. URR: Urea Reduction Ratio. KT/V: Urea clearance index.

Table 3. Cardiac parameters before and after taking sacabitril/valsartan.

\begin{tabular}{ccc}
\hline & Before & After \\
\hline Right ventricular diameter & $23 \mathrm{~mm}$ & $12 \mathrm{~mm}$ \\
Ventricular septal thickness & $14 \mathrm{~mm}$ & $11 \mathrm{~mm}$ \\
Left ventricular diameter & $59 \mathrm{~mm}$ & $46 \mathrm{~mm}$ \\
Pulmonary artery pressure & $56 \mathrm{mmHg}$ & $14 \mathrm{mmHg}$ \\
LVEF & $28 \%$ & $66 \%$ \\
NT-proBNP & $385,000 \mathrm{pg} / \mathrm{ml}$ & $1092 \mathrm{pg} / \mathrm{ml}$ \\
\hline
\end{tabular}

LVEF: Left Ventricular Ejection Fraction. NYHA: New York Heart Association.

The case we describe here is an ESRD patient undergoing regular hemodialysis with severe heart failure. The patient underwent echocardiography showing a series of heart failure symptoms including decreased ejection fraction, pulmonary hypertension, severe mitral and tricuspid regurgitation, etc. She also had hypertension. She received the dose of $50 \mathrm{mg}$ sacubitril/valsartan twice a day, $23.75 \mathrm{mg}$ of metoprolol once a day and $20 \mathrm{mg}$ of spironolactone three times a day. After a period of active treatment, the symptoms of heart failure of this ESRD patient with hemodialysis have been significantly improved. High blood pressure was effectively controlled without symptomatic hypotension and 
NT-proBNP level decreased from $385,000 \mathrm{pg} / \mathrm{ml}$ to $1092 \mathrm{pg} / \mathrm{ml}$. In terms of safety, during the use of sacubitril/valsartan, the patient did not experience heperkalemia and other side effects. Previous studies had also reported the efficacy of sacubitril/valsartan in patients with ESRD, a 67-year-old man with heart failure with reduced ejection fraction due to an ischemic cardiomyopathy and renal insufficiency undergoing hemodialysis. Because of worsening heart failure with no other therapeutic options, a treatment with sacubitril/valsartan was started. After initiation of sacubitril/valsartan, there was a symptomatic improvement with a clear reduction NT-proBNP, accompanied by a decrease in filling pressures [11] A retrospective study analysed the clinical and laboratory data of $23 \mathrm{HFrEF}$ patients, found that sacubitril/valsartan could reduce the hsTnT (high-sensitive troponin) and sST2 (soluble ST2) levels and improve LVEF in HFrEF patients with ESRD, which is the first study to show the effectiveness and safety of sacubitril/valsartan in ESRD patients with HFrEF [10].

In conclusion, we found that sacubitril/valsartan could effectively and safely improve the symptoms of heart failure in this patient with ESRD on regular hemodialysis.

\section{Conflicts of Interest}

The authors declare no conflicts of interest regarding the publication of this paper.

\section{References}

[1] Rangaswami, J. and Mccullough, P.A. (2018) Heart Failure in End-Stage Kidney Disease: Pathophysiology, Diagnosis, and Therapeutic Strategies. Seminars in Nephrology, 38, 600-617. https://doi.org/10.1016/j.semnephrol.2018.08.005

[2] Lv, W.L., Ding, X.Q., Teng, J., et al. (2010) Comparison of Death Causes between Patients with Hemodialysis and Peritoneal Dialysis. Nephrology Dialysis Transplantation, 19, 36-41.

[3] Zhou, R., Chen, F., Huang, X.L., et al. (2019) Correlation Analysis between sST2 and Short-Term Prognosis in Maintenance Hemodialysis Patients Combined with Heart Failure. Chinese Journal of Microcirculation, 29, 52-56.

[4] Go, A.S., Chertow, G.M., Fan, D., et al. (2004) Chronic Kidney Disease and the Risks of Death, Cardiovascular Events, and Hospitalization. The New England Journal of Medicine, 351, 1296-1305. https://doi.org/10.1056/NEJMoa041031

[5] Krediet, R.T., Boeschoten, E.W. and Oekker, F.W. (2012) Are the High Mortality Rates in Dialysis Patients Mainly Due to Cardiovascular Causes. Nephrology Dialysis Transplantation, 27, 481-483. https://doi.org/10.1093/ndt/gfr518

[6] Tonelli, M., Karumanchi, S.A. and Thadhani, R. (2016) Epidemiology and Mechanisms of Uremia-Related Cardiovascular Disease. Circulation, 133, 518-536. https://doi.org/10.1161/CIRCULATIONAHA.115.018713

[7] Chirakarnjanakorn, S., Navaneethan, S.D., et al. (2017) Cardiovascular Impact in Patients Undergoing Maintenance Hemodialysis: Clinical Management Considerations. International Journal of Cardiology, 232, 12-23. https://doi.org/10.1016/j.ijcard.2017.01.015

[8] Haynes, R., Judge, P.K., Staplin, N., Herrington, W.G., et al. (2018) Effects of Sacu- 
bitril/Valsartan versus Irbesartan in Patients with Chronic Kidney Disease. Circulation, 138, 1505-1514. https://doi.org/10.1161/CIRCULATIONAHA.118.034818

[9] McMurray, J.J., Packer, M., Desai, A.S., et al. (2014) Angiotensin-Neprilysin Inhibition versus Enalapril in Heart Failure. The New England Journal of Medicine, 371, 993-1004. https://doi.org/10.1056/NEJMoa1409077

[10] Lee, S., Oh, J., Kim, H., et al. (2020) Sacubitril/Valsartan in Patients with Heart Failure with Reduced Ejection Fraction with End-Stage of Renal Disease. ESC Heart Failure, 7, 1125-1129. https://doi.org/10.1002/ehf2.12659

[11] Heyse, A., Manhaeghe, L., Mahieu, E., et al. (2019) Sacubitril/Valsartan in Heart Failure and End-Stage Renal Insufficiency. ESC Heart Failure, 6, 1331-1333.

https://doi.org/10.1002/ehf2.12544 